\title{
Womenomics and Migrant Workers Policy: Can They Solve Labor Shortage in Japan?
}

\author{
Emmanuel Pradipta and Bevaola Kusumasari \\ Department of Public Policy and Management, Faculty of Social and Political Sciences, \\ Universitas Gadjah Mada, Yogyakarta, Indonesia
}

Corresponding Author: Emmanuel Pradipta (email: emmanuelpradipta@gmail.com)

\begin{abstract}
Aging population threatens economic conditions in Japan which results in a condition of labor shortage, furthermore the government provides Womenomics' and accepting migrant workers policy to solve the issue. This research aims to give an understanding about Japan's labor shortage condition and how it can be solved by Womenomics and accepting migrant workers. Therefore, this research emphasized the labor shortage conditions and the failure factors of Womenomics' and accepting migrant workers in Japan. Essentially, this study applied the qualitative case study method by referring to the literature review conducted by previous studies. The findings of this research are meant providing suggestions to Japan's government about how important it is to enforce appropriate policies to tackle labor shortages and to minimize policy failure of policy implementation.
\end{abstract}

Keywords: aging population; labor shortage; womenomics; migrant workers; policy implementation

\section{Introduction}

As regards Japan's population condition, Japan has experienced the phenomenon of aging population (Toru, 2013). Aging population happens when there are increasing number of unproductive ages or elderly who live in society compared to the productive ages or young generation in a country (Dallin, 2013). The Japanese population of elderly people is steadily increasing compared to the productive ages, thereby it can be categorized as an aging population condition (Dallin, 2013). There are two main reasons why Japan experiences an aging population, first technological advancement in medicine have led to Japanese people living longer; also, economic constraint such as expensive living costs have become the reason for low birth rates (Roser, 2013). Japan has the longest life expectancy in the world, and at the same time Japan has the lowest birth level in the world (Fukuda, 2016). In Japan, the percentage of elderly people aged 65 years old above surpassed $10 \%$ of the total population in 1985. In 2020, the total of population aged 65 years old above reached $28,8 \%$ from the total of population (Statistics Bureau of Japan, 2021). Therefore, Japan's birth rate is declining and the country has to face the consequences of aging population (Konishi, Tamaki and Yoshinaga, 2018).

There are two types of consequences from an aging population: social and 
economic. For social consequence, rural depopulation becomes the main issue by the existence of an aging population. It makes the majority of productive ages only want to live in big cities which ends human resources scarcity in rural areas (Sigurðsson, 2017). The other consequence is that aging population in Japan has bad impacts to the Japan's economy such as the decline in demand and a decrease in real GDP. It means an aging population causes a decreasing tax base, increasing government expenditure, and economic activity decelerates (Katagiri, 2012). The decline in demand and decrease in real GDP originated from shrinking population and labor shortage. Therefore, the Japanese government faces this crucial problem for economic development, which is plagued by the labor shortage due to an aging population (Morita, 2017).

The Prime Minister of Japan, Shinzo Abe, produced an alternative policy in order to solve the problem of the labor shortage. The policy was called "Womenomics" which empowers woman to take more participation in developing Japan's economy by taking up a career (Helen, 2015). Another alternative is that the implementation of accepting migrant workers to fill the productive-age scarcity (Masahiko, 2010) because the improvement of the productivity levels by taking advantage of human resources will definitely expand the Japanese economy. Both Womenomics and accepting migrant workers policy become important topic to be discussed since these two policies are what the Japanese government undoubtedly relies on (Sigurðsson, 2017)

Studies concerning implementation of Womenomics and accepting migrant workers to tackle labor shortage have also been conducted by several scholars. First, Serban (2012) analyzed the influence of demographic conditions on labour market. The aging and decreasing population prospects require special attention due to older labor force is less adaptable to the changing conditions of Japan's economy. Then, Japanese labor shortage needs to be addressed by some convergent solution of birth stimulation and of increasing human capital (Serban, 2012). Another scholar analyzed the Womenomics can be one of alternative to tackle the labor shortage. It explained the historical context of current Womenomics policy, provides a critical analysis of implementation strategies discussing progress and socio-structural obstacles, and concludes with an assessment of the viability of Womenomics for Japan (Helen, 2015). Another scholar also analyzed that implementing Womenomics is the policy to tackle labor shortage while also addressing the gender equality issue. However, there were blind spots in Womenomics that focus on increasing work opportunities for an elite segment of women. While recognizing that the promise of promoting more women to higherlevel positions does address long-standing frustrations about the institutionalized sexism of political and corporate culture in Japan (Schieder, 2014). Regarding the implementation of Womenomics, Yuiko (2014) explained on the importance of 'zerowaiting list daycare,' since it supports women who want to have children and participate in the workforce (Yuiko, 2015). On the other hand, Masahiko (2010) noticed the implementation of accepting migrant workers to fill the productive-age scarcity is an important project. This policy is to address the workforce shortage by implementing the Technical Intern Training Program (TITP) by maximum 3 years of contract (Masahiko, 2010).

There are still few studies that address on the policy implementation of government to tackle the labor shortage caused by the aging population since the previous studies do not elaborate two policy implementations in accepting more migrant workers and Womenomics to solve labor shortage in the context of an aging population. Therefore, this research focuses on both implementation of Womenomics and accepting migrant workers 
to tackle labor shortage in the context of aging population.

This research addresses how the labor shortage conditions in Japan and how Japan's policy implementation solves the labor shortage which is caused by an aging population. This research expected brings ideas for Japanese government about the importance of appropriate policy implementation to give solutions to labor shortage matters and reduce the possibilities of policy failure. This article is divided into several parts. First, the views on literature are presented through compiling studies on the definitions and concepts of labor shortage and policy implementation by various authors and scholars. Second, the research methodology would be elaborated by qualitative method, starting from collecting secondary data. Third, the results from the findings would be reported, which illustrates Japan's labor shortage, the implementation of Womenomics, and the implementation of accepting more migrant workers. Fourth, the reviewed findings and generated dimensions of capability would be examined deeper by understanding the case studies to provide answers for the research questions. Finally, the paper is concluded with final remarks on the research, the limitations, and additional developments for future studies on the subject.

\section{Literature Review}

\section{Labor Shortage}

The definition of Labor shortage cannot be separated from the idea of Human Resources (HR). Advanced human resource (HR) planning needs to be carried out by a high caliber HR management team. Although the importance and role of the HR department is finally recognized by many business owners, the current labor shortage means support for HR is insufficient. Improving the capabilities of HR staff is the responsibility of business owners, who should provide more support to HR staff (BSR, 2010).

Labor shortage happens when "there is a shortage of members of a specific profession if the number of available workers is less than the number needed, as established by some social criterion or goal" (Blank \& Stigler, 1957). By the existence of this definition, other scholars defined labor shortage as "a circumstance existing over an extended period of time when the employers were not able to hire at going wages or salaries sufficient numbers of qualified persons to fill positions for which there were budgeted funds and for which personnel were required to satisfy existing demands for services" (Franke and Sobel, 1970). However, the recent condition the labor shortage itself occurs by many types of shortages, such conditions affect the demand and supply of labor (Boswell, Stiller, \& Straubhaar, 2004). All organizations and companies need individual talent which is relevant to the objectives of the organizations or companies. If organization want to operate in the long term, they need to have talent workers who can adapt with change or even lead changes (Boxall and Purcell, 2011). Organizations which hire and maintain individual talent to create a "human capital advantage' (Boxall, 1996). Many organizations in western countries face an aging population. As a consequence, there will be a labor shortage a few decades later (Cappelli, 2005). When the organizations experience the labor shortage, then they will face problems in finding individuals to benefit from human resources. Organizations proactively will try to find the solution on how to tackle the problems of the decrease in labor supply.

Dutch labor market research illustrates that there is a demand for replacing laborers in the next five years to address the retirement of laborers. This research predicted more than two million workers would be replaced, nevertheless the growing labor population will not be enough to replace all the labor 
shortages (ROA, 2011). Companies looking for employees with economic/administrative or agricultural, pedagogical, care, and technical backgrounds will experience serious problems (ROA, 2011).

Boswell stated one of the many types of shortages is an aggregate labor shortage. This type of shortage exists when there is a shortage in aggregate supply of labor with full employment (Boswell, 2004). Thus, there are many literature studies that define this aggregate labor shortage as "hard-to-fill vacancies' or quantitative shortage which caused by low number of productive ages (Zimmerman, 2005).

\section{Policy Implementation}

According to Charles (1991), implementation is part of the public policy process which can be categorized as the next step after the agenda setting, formulation, adoption, and subsequent stages of the assessment. What is meant by policy implementation is the ability to form further relationships in a series of cause and effect linking actions with goals. It is an effort to establish a linkage between program actions with program goals/objectives to be achieved (Suparno, 2017).

Policy implementation has been characterized by numerous researchers from different points of view. The usage is the execution phase of the policy process. Implementation is an activity in a public regulationcycleapplied sothataregulationcan achieve its goal. Regulation implementation series can be observed clearly starting from the created programs up to the regulation implementation steps (Subarsono, 2011). Another definition of implementation are about Policy Implementation which is defined as what happens between the publication of an apparent initiation on the part of the government do something, or to stop doing something, and the ultimate impact in the world of action (O,toole, 2000 in Fischer et all, 2007). Another scholar stated that it is enacting the law where different stakeholders, organizations, procedures, and techniques work together to place policies into practice with the end goal of accomplishing the policy objective (Stewart et al., 2008). The implementation can be explained as a process which focuses on the output and outcome, and thus, it includes various actors of organizations and techniques of control. It is about interaction processes between setting goals and the actions directed toward accomplishing them (Pressman \& Wildavsky, 1973).

The most common definition of implementation positions it as the gap between policy's expectation and the results (Smith \& Larimer, 2009). Therefore, it is obvious that if the outcomes of policy implementation are not up to the policy makers' expectation, it can be categorized as a failed policy. This is why in implementation studies, the comprehension about the success or failure of public policy elucidates factors which influence it.

Van Meter and Van Horn (1975) stated that the uncertainty of policy objectives and standards can make it difficult for the implementor to understand and at the same time give rise to the diverse dispositions of various actors involved in the implementation process which ultimately do not support the smooth and successful implementation of policies. Therefore, the objectives / targets and policy standards are crucial factors in the implementation process.

According to Mazmanian and Sabatier (1989) there are several things that affect the success or failure of implementation. First, the independent variable, namely whether or not the problem is easily controlled with regard to indicators of theoretical and technical problems of implementation, diversity of objects, and changes as desired, Second, intervening variables, 
namely the ability variable to structure the implementation process with indicators of clarity and consistency of objectives, the use of causal theory, the accuracy of resource allocation, hierarchical cohesiveness among implementing agencies, implementing rules of implementing agencies, and recruitment of executing officials and openness to outsiders, Third, variables outside the policy that affect the implementation process with regard to indicators of socio-economic and technological conditions, public support, attitudes and resources from constituents, higher official support, and commitment and leadership qualities from implementing officials (Mazmanian \& Sabatier, 1989).

Reviewing to Grindle (1980), the success of implementation depends very much on the content of the policy, that is how much interests are effected (i.e., the greater the interests are, the more difficult it is to implement). Likewise, the success of implementation depends very much on the type of benefits that the policy intends to produce. The more tangible the benefits generated the easier it is to implement. The degree of change also effects success in implementation. If the degree of change desired by the policy is large and broad, then its implementation is more difficult and vice versa. If the degree of change is small then the policy is easy to implement. Successful implementation is influenced by the nature or type of interests to be achieved by the policy itself. Certain types of policies will have a certain impact on the activity of the implementation process (Grindle, 1980). The final outcome of policy implementation is important in defining whether the policy is successful or not due to it shows the linkage between expectation and result, then the strength of the policy's impact towards society also indicates the effectiveness of policy. In addition, it also can be measured by considering the influence of policy implementation at the national level, thereby the impact should be as policy makers expected (Grindle, 1980).

Regarding the concepts that be used in this research, it uses the concept of aggregate labor shortage (Zimmerman, 2005). It is the most suitable concept to explain about the condition of labor shortage in Japan since the previous concepts do not explain the labor shortage which caused by low number of productive ages. Moreover, this research also uses the concept of policy implementation by (Grindle, 1980). It is the most appropriate concept to analyze whether the policy is successful or not due to all the data that can be used in the indicators, such as the interest affected, the type of benefit, the degree of change and gap between expectation.

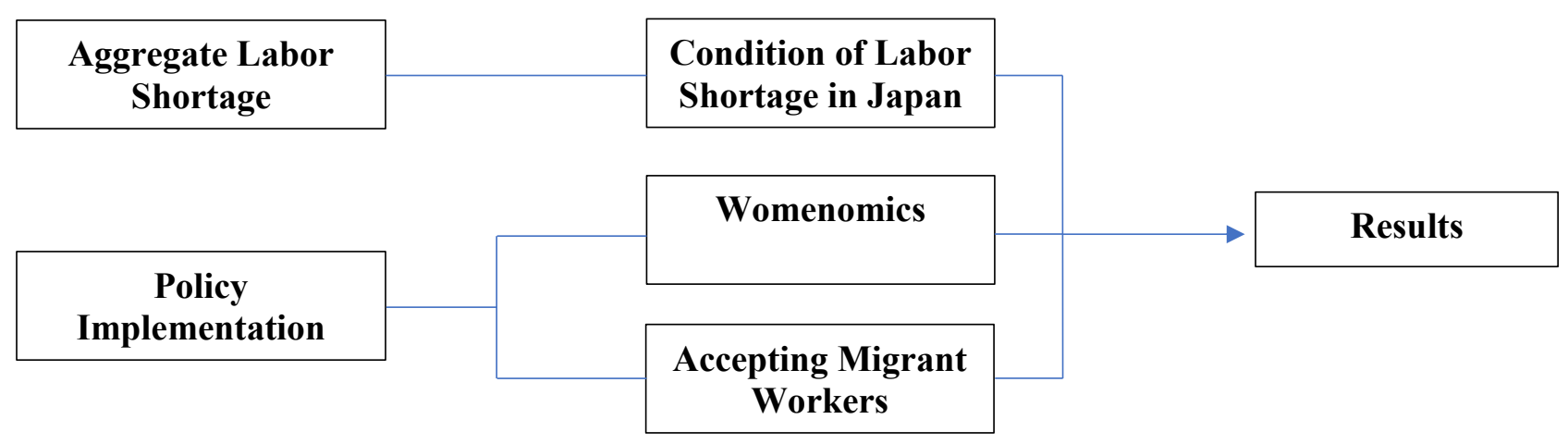


Researcher uses the concept of aggregate labor shortage to understand the condition of labor shortage in Japan. Then, the concept of policy implementation is also used to explain whether the implementation of Womenomics and accepting migrant workers are successful implemented to overcome the labor shortage in Japan. Finally, researcher finds the results.

\section{Research Methodology}

As regards research methodology, there are many researchers use a qualitative case study method for the purpose of analyzing the policy implementation to tackle the issues (Brigitte, 2003). This study carried out by using qualitative research method. Qualitative research consists of several types. One qualitative method is a qualitative case studies (Creswell, J., \& Creswell, J., 2018). Researcher used a qualitative case study method to give an understanding of Japanese policy implementation to solve labor shortage as the alternative to reduce the gap between expectation and result and possibilities of failure in policy implementation.

Regarding the data obtained, researcher used qualitative case study methodology by using secondary data analysis (Creswell, J., \& Creswell, J., 2018). Secondary data are collected from certain resources which have primary data (Boslaugh, 2007; Johnston, 2014). There are different types of resource data obtained by the researcher in this analysis, the data can be found by books and journals to understand and analyze concepts of research and elaborating the research objectives in this case study (Martin, Cunha, and Serra, 2018). Evidence is taken from many discussions about this case study especially in books and journal articles. Therefore, the researcher conducts the analysis by using secondary data since it can be categorized as the most appropriate.
Analysis using secondary data is divided into four phases: developing the research question, identifying a secondary data set, evaluating a secondary data set, and preparing and analyzing secondary data (Johnston, 2014; Wallace Foundation). First, authors identified the general topic, then it consists of reading through existing papers to see whether there is a gap in the literature to fill. At this point, authors discovered that previous research has not investigated the Japanese labor shortage conditions after implementing policies to solve the issue and how Japan's policy implementation solves the labor shortage which is caused by an aging population. Second, after reviewing the literature and specifying research questions, authors decided to rely on secondary data. Authors discovered that there is past data that perfectly reusable in this research, those data include the unemployment rates and active jobs opening to applicant's ratio condition, implementation of Womenomics, and implementation of migrant workers. By the existence of those case studies, the research question can be answered more thoroughly. Third, checking the background of these organizations and research, authors concluded that the research is dependable and identified the aim of the original study by understanding the findings of secondary data to understand that this data relevant, Data has been collected by professionals, the actions taken are reliable and valid, and the methodology is adequate. Authors can be sure that new research questions to fill the gap can be answered adequately with existing data. Last, authors used secondary data analysis compilation to analyze the several findings using existing concepts in labor shortage and policy implementation (Johnston, 2014; Wallace Foundation). 


\section{Findings}

\section{General Overview of Labor Shortage Condition in Japan}

As indicated by government projections, a "positive scenario" would be that real average growth of 2 percent and the labor participation rate increases to 60.1 percent by 2030 , yet the workforce still declines to 62.9 million. In a "negative scenario," the employment workforce is projected to decline from 63.0 million in 2010 to 54.5 million in 2030 (Ganelli and Miake, 2015). The active number of job opportunities to applicants has been rising while the unemployment rates have declined after the global financial crisis in Japan in 2009. It reached the lowest level in 2017, at the same time the ratio for active job openings-to-applicants were 1.52 position per capita which is the highest level in the graphic (Yoshio, 2018).

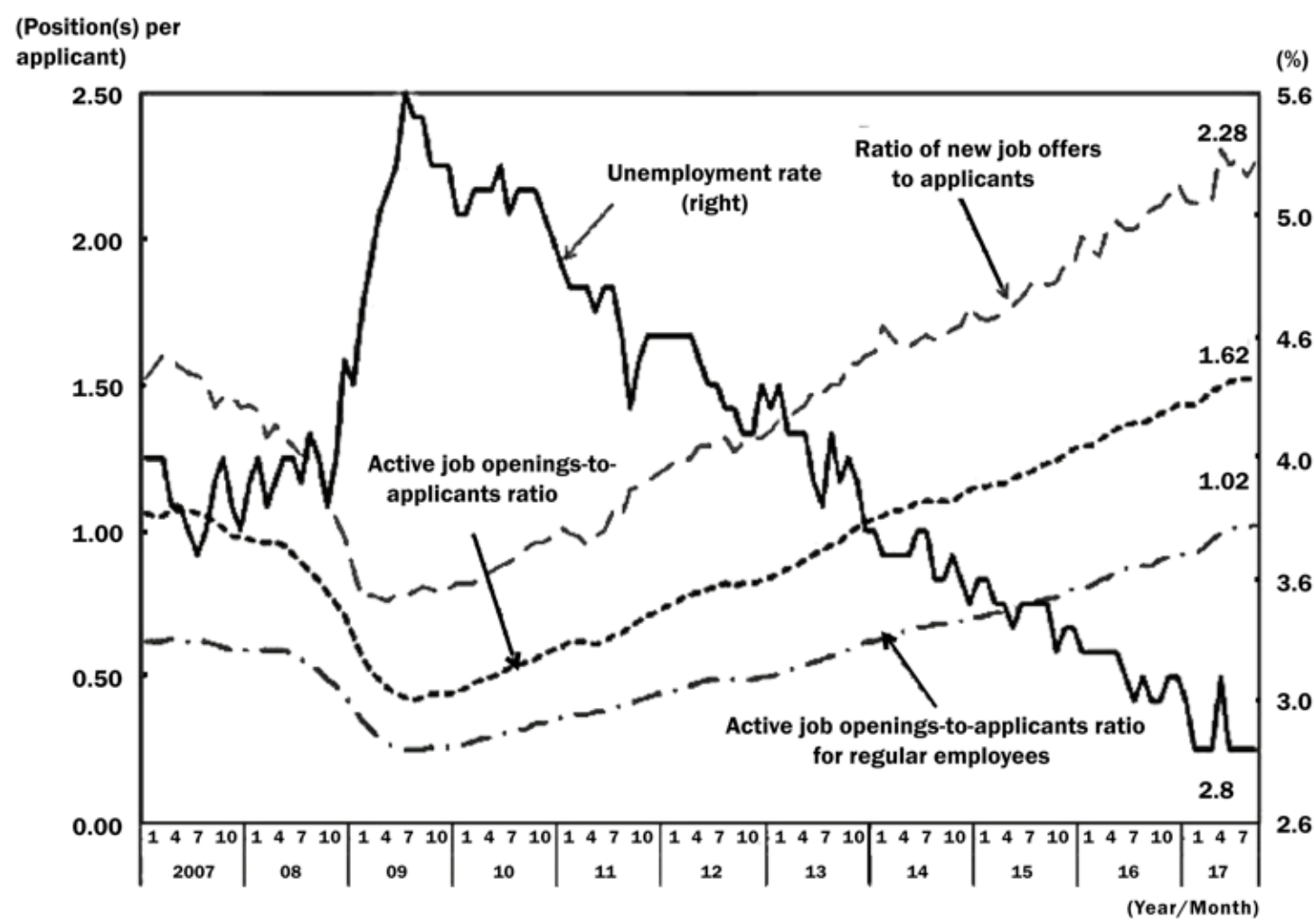

Source: Prepared by Office of Counsellor for Labour Policy Planning of MHLW, based on MHLW's Report on Employment Services and Statistics Bureau, MIC's Labor Force Survey

According to the discussion that researcher conducted with Prof. Futoshi Kinoshita, University of Tsukuba of Humanities and Social Sciences Professor experts in demographic transition, demographic structure, fertility, mortality, and modernization, he explained that there is factor which brings on this current shrinking workforce which caused by the existence of population decline. Economic insecurity makes Japanese people do not want to have a birth, this condition brought by Japanese government which focuses on improving their economy by taking advantages from human resources exaggeratedly compared to give positive birth rate stimulation policies to maintain the enough number of workforces in long term. There is a larger improvement in labor force condition for older employers, and companies often maximize older employees to maximize productivity. Furthermore, the number of labor force participants usually 
decrease for women between the late 20s and the 30 s because many Japanese women resign from their jobs to get married or raise children. However, many women also remain a part of the labor force from their late 20s through the $30 \mathrm{~s}$. One reason for this is that women delay marriage and childbearing. Also, many women choose not to get married (Ganelli and Miake, 2015).

Regarding the main reason why Japan faces lack of workforce, as it mentioned before about population aging, the category of productive ages is smaller compared to unproductive ages. This clearly has a strong impact on the ability to maintain the massive growth of retired citizens (Kolbeinn, 2011). Furthermore, many women resign from working to get married or raise children due to the long waiting list for the public daycares. Even though there are many private daycares which have short waiting lists, a middle-class Japanese family would struggle to afford it (Schieder, 2014). For those women who decide not to resign from their job will delay the marriage.

Hence, by the existence of disproportionate ages in Japan, the cost that the government can afford for the social security and retirement plans will continue to decrease (Kolbeinn, 2011). The lack of workforce has serious negative impacts on the Japanese economy due to the decreasing population. Thus, companies in Japan are not able to find workers that they need to carry out specific projects (Ganeli and Miake, 2015).

\section{The implementation of Womenomics}

In 2012 the International Monetary Fund (IMF) discharged a working paper titled "Can Women Save Japan?" The paper examines and analyzes to what extent increased participation of women can tackle the trends of the elderly population and potential development. Japan's government is expected and advised to create policies which help to improve women's participation and also reduce inequality between males and females. This is important for Japan since it is categorized at a very low level for gender equality among industrialized and developed countries (Steinberg and Nakane, 2012). Prime Minister Shinzo Abe was supporting the agenda of economic growth and reform which is known as Abenomics. This is a series of policies that originated by Abe's ideas to raise up Japan's economy with the headline "Japan is Back" and focused on three arrows: fiscal stimulus, monetary easing, and structural reform. Specializing in the involvement of women and targeting women as alternatives for human resources as a part of strategies for national structural reform in alleviating Japan's demographic crisis becomes both national and international policy. As a part of the structural reform of Abenomics, Shinzo Abe was adopting and implementing the policies of Kathy Matsui highlighted in her paper titled Womenomics: Female buy the Female economy in 1999 (Yoshino and Taghizadeh Hesary 2014). Abe has promised success for Japanese women and the Japanese economy in the context of economics and politics (Linda, 2017).

There are several targets expected by Japan's government throughout Womenomics Hiroko (2018): First, Increasing the percentage of women participation in labor force in the context of nationss development was unfamiliar, so the recruitment process in Womenomics should consider gender equality. Women make up more than ${ }^{\circ}$. per cent of the total population in Japan, therefore it can be expected to fill the government's target. Targets set according to the age stage in Womenomics include increasing the workforce of women aged 25 - 44 becomes $77 \%$ in 2020 , increase the workforce of women aged $20-34$ becomes $79 \%$ in 2020 , increasing the workforce of women aged 2064 becomes $80 \%$ in 2020, increasing the workforce of women aged 60- 64 becomes $64 \%$ in 2020. Second, achieving 30 per 
cent women's leadership roles in 2020. This program creates transparency for women leadership positions such as professors, heads of departments, managers, governors, ministers, vice mayors, etc. Both the public and private sectors are obligated to disclose the number of women in leadership positions due to this policy which will pressure companies to improve women's role in leadership positions. Third, Increasing the percentage of women to return to work after having their first child. The majority of career women who decide to quit their jobs are aged 20 to 34 , which can be classified as productive ages. Therefore, the government effort will encourage women to return to work. Fourth, accelerating and increasing the daycare facilities and after school clubs. The point of this policy is to improve the capacity of daycares to achieve a 'zero childcare waiting-list.' Indirectly, this policy will open opportunities to achieve those three targets of Womenomics, thus women can return to work because childcare will be guaranteed. Fifth, increasing the percentage of males who take care of their children. This policy is expected to be achieved by the year of 2020. There are many stereotypes that Japanese husbands think it is not their responsibility to take care of their children. Married women play an important role in taking care of children instead of husbands (Helen, 2015). Last, Reducing the working hours of companies from more than 60 hours to less than 60 hours a week. There are many companies that have working hours of more than 60 hours per week in Japan, leaving limited time for personal life. The target of this policy is expected to be accomplished in at least 5 per cent of Japan (Hiroko, 2018).

According to Goldman Sachs Global Investment Research, there are several significant benefits of Womenomics. First, it boosted Japan's female labor participation rate from $63 \%$ in 2013 to $71 \%$ in 2019 . Second, the maternity cost by both parents in 1999 changed so that two-thirds of salary was replaced during the first six months. Third, it required both public and private organizations to remove gender diversity plans. Last, it introduced labor reforms to prevent overworking time (Matsui, Suzukui, \& Kazunori, 2019).

Japan's government failed to achieve the target of the policy to improve women participation by 30 per cent in leadership positions, therefore the government has changed the target from 30 to 10 per cent in 2020 (Matsui, Suzukui, \& Kazunori, 2019). Then, there were still a massive number of children on the waiting-list to enter authorized daycare centers in Japan which accounted for 16,772 (Kyodo, 2019). Furthermore, there are cultural impediments toward Womenomics, first, social norms tend to allow women to assume the family's main reproductive and caring tasks, with women assuming crucial responsibilities for housework, child care, and the care of parents. Contributing to this is the lack of early childcare facilities. A further constraint is the notion of Sinaiji Shinwa, a traditional belief that mothers will care for children until the age of three and continuing strain upon mothers for the growth and education of their children. Second, corporate culture promotes men not only to abandon their domestic and childcare duties for women, but also makes it incredibly difficult for women to reintroduce themselves into a competitive work culture after taking childcare abandon with their emphasis on permanent employment as a determinant of job and advancement opportunities. Employers also do not expect a working mother to be able to work as intensively and with the dedication level of their male counterparts (including working fathers) which is why women are side-lined from many career-enhancing roles and training. The returning women are urged to work as non-regular workers who face fewer demands for loyalty and time as non-core workers (Nañes, 2018). 
The implementation of Accepting Migrant Workers

The discussion about aging population becomes a serious topic among stakeholders each year with various kinds of debates and developments. The Japanese demand for the improvement of the workforce has improved due to the aging population in Japan (ADBI, OECD, and ILO, 2015). With respect to immigration policy in Japan, the number of foreigners who live in Japan has rapidly grown in recent years from 850,000 in 1985 to 2.6 million in 2017. However, it did not reach the $2 \%$ total population goal. For comparison, Western European countries had between $8 \%$ to $25 \%$ foreign nationalities. Furthermore, one-fifth of migrant workers in Japan had a visa intended for labor immigration who were restricted to highly skilled labor. With the labor shortage, the Japanese government has shifted to opening the door to migrant workers even though foreign workers in Japan are still taboo (Yunchen, 2018). The Ministry of Justice has drastically extended the visa quotas and foreign workers for construction areas to prepare the 2020 Olympics in Tokyo. Moreover, the Cabinet office of the Prime Minister released an annual policy report which focuses on the improvement of foreign talent which includes unskilled labor and professional workers as a tool to recover the nation's economy. The Japanese government announced its intention to accept up to 500,000 workers especially in nursing, lodging, construction, shipbuilding, and agriculture (Rebekah \& Vukovic, 2019).

The Japanese government still focuses on homogenous societal values. The agenda to open the doors for migrant workers has so many pros and cons from the public because they consider the possibility of immigrants who come to Japan a threat towards their country because they believe diversity might have negative influences to social stability and national security. Japan had experienced a labor shortage in the 1960s the same as other industrialized countries at that time. Instead of accepting a massive number of migrant workers as America and European countries did, they were more focused on using alternative sources such as improving womenss participation (Yunchen, 2018). Japan had experienced the second labor shortage in the middle of the 1980s (Imai and Mori, 1998).

Regarding this second labor shortage, the government amended the Immigration Control and Refugee Recognition Act for recruiting foreign workers with low salaries without violating the closed-door policies, thus they accepted a limited number of foreign professional workers that usually were from Western countries. Regarding this policy, there was a long-term visa for the second and third generation of the descendants of Japanese blood who migrated from Japan. They had special treatment from the Japanese government that allowed them to extend their visa easily, create permanent visas, and go through the naturalization process. Second, there was the Technical Intern Training Program (TITP) which usually originated from Asian countries for up to three years. On the other hand, they often threatened deportation if interns tried to stay longer than three years (Tsuda, 2003).

These different policies from the Japanese government came from the insecurity of Japanese politicians who suspect that workers from Asian countries would establish themselves in Japan the same way as Turkish and Yugoslav individuals who migrated to Germany after the war period. Japan believed workers who are descendants of Japanese blood would easily adapt to Japanese society (Tsuda, 2003). However, the program of TITP has been successful in directing migrant labor to work in small and medium sized businesses which are not attractive enough for native Japanese to work, especially in rural areas (Yunchen, 2018). 


\section{Discussion}

Regarding the labor shortage conditions, the unemployment rate in Japan was 2.8 per cent in September 2017 which is the lowest rate from the graphic shown. Furthermore, the ratio for active job openings-to-applicants were 1.52 position per capita. Therefore, the ratio for active job openings-to-applicants has been rising since 2009 to 2017 and the unemployment rate has been decreasing to the lowest level in 2017 (Yoshio, 2018). This condition shows there are shortages of productive aged individuals in the workforces. The main problem is found in the low birth rates, which result in labor shortages - as was mentioned about aggregate labor shortage (Zimmerman, 2005). It can be categorized as an aggregate labor shortage because companies find difficulties recruiting employees as an impact of aging population.

By the existence of labor shortage, Japan's government produced policies aimed at solving the issue. The Japanese government established Womenomics to fill the labor shortage with the participation of women in the workforce. Based on the findings above, the implementation of Womenomics have accomplished their several targets such as from 63 per cent in 2013 to 71 per cent in 2019, Japan's participation in women's work increased. Additionally, the maternity cost by both parents in 1999 changed so that two-thirds of salary was replaced during the first six months. Third, it included the elimination of proposals for gender diversity from both public and private organizations. Last, labor reforms were implemented to discourage overwork (Matsui, Suzukui, \& Kazunori, 2019). However, Japan has failed to meet its policy goal to increase women's representation by $30 \%$ in leadership positions, from $30 \%$ to $10 \%$ in 2020 (Matsui, Suzukui and Kazunori, 2019). In addition, the waiting list for approved day care facilities for 16,772 children in Japan remained huge (Kyodo, 2019).
The success or failure of policy implementation according to Grindle (1980) depends on several factors. First, the interest affected should have positive impacts to the results of the policy implementation. However, the interest affected can't be solving the main problem that is labor shortage which caused by an aging population evidenced by the Japanese labor conditions that there are low number of unemployment and the high demand of workers which indicate there is aggregate labor shortage (Yoshio, 2018). Then, the type of benefit of Womenomics is not in line the main goal of solving labor shortage which caused by the aging population. There is massive number of waiting lists which makes the Japanese Women not want to participate in the workforces and have birth (Yuiko, 2015), while policy implementation should give birth stimulation and human capital in order to solve aggregate labor shortage (Serban, 2012). Furthermore, the degree of change is too large because there is no consistency of objective from the policy. Therefore, the main objective of Womenomics is to solve the issue of labor shortages which is caused by an aging population, however it changed to tackle the gender bias (Schieder, 2014), as a result there is massive gap between expectation and results of Womenomics' implementation. Therefore, this research finds the implementation of Womenomics a failed policy implementation because there is no capability to fulfill factors mentioned above.

Regarding another policy to tackle the issue, there is implementation of accepting migrant workers in Japan. This policy implementation aims to fill the labor shortage condition namely Technical Intern Training Program (TITP). It succeeded to fill the labor shortage in rural areas because Japanese natives want to work in urban areas (Yunchen, 2018). However, the Japanese government was not serious about this policy. It showed there is discrimination against TITP which 
originated in Asian countries to prevent migrant workers from getting permanent visas since they have to go back to their home country after three years (Tsuda, 2003). The Japanese government still is not focusing on this policy due to evidence that Japan considers accepting more migrant workers as a threat to national security, it is because Japanese government maintained the homogenous value to prevent the possibilities of Japanese outsiders disrupting national security (Masahiko, 2010).

With respect to this policy, in general the interest affected does not have positive impacts toward the aggregate labor shortage in Japan since the unemployment rates are still low and the job openings-to-applicants ratio are high (Yoshio, 2018). However, it has tangible benefits toward the lack of workforces in rural areas, but it has no massive impact towards Japanese labor shortage as a whole due to certain reasons. The reason is strongly related with the cultural constraint which shows the Japanese government wants to maintain the homogenous society, then considers migrant workers as a threat for Japanese culture (Masahiko, 2010). Last, the degree of change of implementation is small which means this policy is easy to be implemented because the only focus of the objective is to solve the labor shortage, in fact it has no positive outcomes to tackle the labor shortage in Japan as a whole. Based on the factors above, it shows that the implementation of accepting migrant workers is not successfully implemented due to the government not focusing on improving the number of migrant workers. Whereas if the government focuses on supporting this implementation, it is very clear overcoming labor shortage caused by aging population. It showed that the government forced open the doors to migrant workers in massive number for the sake of the Tokyo Olympics 2020 (Rebekah \& Vukovic, 2019). It indicates the only way to solve the labor shortage in Japan is taking advantage of workers from overseas.

\section{Conclusion}

The case study of Japanese labor shortage illustrates the need for government to provide good policies to tackle the issue. The government should identify from various factors of the problem to improve the decisionmaking process. At least, the government can reduce the gap between expectation and the results of the policy implementation, then providing positive outcomes from the policy implementation on problems. By implementing proper policies according to the main problem that is aging population, it will establish advantages for Japan's labor conditions.

The results by implementing Womenomics and opening the door to migrant workers has no significant impact on the labor shortage condition in Japan. Therefore, this research finds that Japan should maximize policies by collaborating between those policies. First, the main point is that Japan should open the door to migrant workers in massive numbers because there is no other option to tackle the labor shortage. Migrant workers can be allocated in strategic areas where Japanese society has no interest to work. Moreover, the Womenomics implementation can be maximized by using migrant workers to improve infrastructure to build public daycares, and it may also be possible to allocate certain migrant workers in the daycares because of the limited number of workers in this area. It is very important to improve the capacities of public daycares to achieve the targeted policy called "zerochildcare" which means there is no waiting lists. Japanese women will not be afraid of having children which will improve the birth rates in Japan since the aggregate labor shortage in Japan should be solved by the stimulation of birth rates. This would have long term impacts.

This study was a case study conducted by analyzing two policies in solving the problem of labor shortage in Japan. Future research 
may assess the potential of accepting massive number of migrant workers and how to prevent risk.

\section{References}

ADBI/OECD/ILO 2015. Building Human Capital through Labor Migration in Asia, Tokyo, http://www.oecd.org/els/mig/ building-human-capital.pdf.

Blank, D.M. \& Stigler, G.J. 1957. The demand and supply of scientific personnel. New York: National Bureau of Economic Research.

Boslaugh, S. 2007. Secondary Data Sources for Public Health: A Practical Guide (Practical Guides to Biostatistics and Epidemiology). Cambridge: Cambridge University Press. doi:10.1017/ CBO9780511618802

Boswell, C., Stiller, S. \& Straubhaar. T. 2004. Forecasting Labour and Skills Shortages: How Can Projections Better Inform Labour Migration Policies? European Commission; Hamburg: HWWA, 7-20.

Boxall, P. 1996. The strategic HRM debate and the resource-based view of the firm. Human Resource Management Journal, 6(3), 59-75. doi: 10.1111/j.17488583.1996.tb00412.x

Boxall, P. \& Purcell, J. 2011. Management, work \& organisations: strategy and human resource management. New York: Palgrave Macmillan.

Brigitte, S. 2003. Can Qualitative Research Inform Policy Implementation? Evidence and Arguments from a Developing Country Context. Forum: Qualitative Social Research.

BSR. 2010. A Study on the Labor Shortage and Employment Guidelines for Manufacturers in China. Primark, 4-7.

Cappelli, P. 2005. Will there really be a labor shortage? Human Resource Management, 44(2), 143-149. doi: 10.1002/hrm.20056
Creswell, J., \& Creswell, J. 2018. Research Design: Qualitative, Quantitative, a nd Mixed Methods Approaches (5th ed., pp. 16, 187). Los Angeles: SAGE.

Dallin, J. 2016. The Issue of Japan's Aging Population. International Immersion Program Papers. European Commission, DG Employment and Social Affairs. Brussels: European Commis sion; Hamburg: HWWA.

Fischer, Frank. 2007. Handbook of Public Policy Analysis: Theory, Politics and Methods. CRC Press.

Franke, W. \& Sobel, I. 1970. The shortages of skilled technical workers. Lexington: Heath-Lexington Books.

Fukuda, N. 2016. Marriage and fertility behaviour in Japan. 1st ed. Singapore: SpringerNature, pp.1-7.

Ganelli, G., \& Miake, N. 2015. Foreign Help Wanted: Easing Japan's Labor Shortages. IMF Working Papers, 15(181), 1. doi: $10.5089 / 9781513530642.001$.

Grindle, M. 1980. Politics and policy implementation in Third World. Princeton: Princeton University Press.

Helen, M. 2015. Womenomics for Japan: is the Abe policy for gendered employment viable in an era of precarity? The AsiaPacific Journal: Japan Focus, 1-3.

Hiroko, T. 2018. Between Reproduction and Production: Womenomics and the Japanese Government's Approach to Women and Gender Policies. Gender and Political Leadership, 49-64.

Hollifield, J. and Orlando Sharpe, M. 2017. Japan as an 'Emerging Migration State'. International Relations of the AsiaPacific, 17(3), pp.374-375.

Katagiri, M. 2012. Economic Consequences of Population Aging in Japan: effects through changes in demand structure. (No. 12-E-03). Institute for Monetary and Economic Studies, Bank of Japan.

Kolbeinn, B. 2011. Labor Shortage in Japan: The coming population decline and 
its effects on the Japanese economy. Haskoli Island, 14-18.

Konishi, S., Tamaki, E. and Yoshinaga, J. 2018. Biodemography of Fertility in Japan. 1st ed. Singapore: Springer Singapore, pp.7-10.

Kyodo. 2019. Record low of 16,772 children on day care waiting lists in Japan, welfare ministry says. Retrieved from thejapantimes: https://www.japantimes. co.jp/news/2019/09/06/national/japanday-care-waiting-record-low/\#.Xp_ TQy2B3Vo.

Linda, H. 2017. Political Targets: Womenomics as an Economic and Foreign Relations Strategy. Center for Asian Studies, 5-26. Martin, F., da Cunha, J., \& Serra, F. 2018. Secondary Data in Research- Uses and Opportunities. Iberoamerican Journal of Strategic Management (USM), 17 (4), 01-04. Doi: 10.5585/ijsm.v17|4.2723

Masahiko, Y. 2010. The Current Issues on Foreign Workers in Japan. Japan Labor Review, Vol 7, No. 3, 5-18.

Matsui, K., Suzukui, H., \& Kazunori, T. 2019. 20 Years on Womenomics 5.0: Progress, Areas for Improvement, Potential 15\% GDP Boost. Goldman Sachs, 12-14.

Mazmanian, D., \& Sabatier, P. 1989. Implementation and public policy. Lanham: University Press of America.

Ministry of Internal Affairs and Communications. 2021. Statistical Bureau Handbook in Japan 2021. Statistic Bureau of Japan.

Morita, L. 2017. Why Japan isn't more attractive to highly-skilled migrants. Cogent Social Sciences, 3(1), pp.1-12.

Nañes, M. E. 2018. Reality Check: Can "Womenomics" Help Save Japan's Declining Population? University of the Philippines Press 1-15.

Pressman, J. L., \& Wildavasky, A. 1973. Implementation: How great expectations in Washington are dashed in Oakland. Berkley: University of California Press.
Rebekah, S., \& Vukovic, A. 2019. How Can Japan Meet Its Goal of 500,000 Foreign Workers by 2025? By Contracting Out Labor Mobility Programs. Center for Global Development.

Researchcentrum voor Onderwijs en Arbeidsmarkt. 2011. De arbeidsmarkt naar opleiding en beroep tot 2016. Maastricht: Maastricht University.

Schieder, C.S. 2014. Womenomics vs. Women: Neoliberal Cooptation of Feminism in Japan. Meiji Journal of Political Science and Economics 3(1), 53-60.

Serban, A. 2012. Aging Population and Effects on Labour Market. Procedia Economics and Finance, 1, 356-364. doi: 10.1016/s2212-5671(12)00041-x.

Sigurðsson, E. O. 2017. Impacts of Population Aging in Modern Japan and Possible Solutions for the Future. Haskoli Island, 17-26.

Smith, K. B., \& Larimer, C. W. 2009. The public policy primer. Boulder: Westview Press. Hudson.

Steinberg, C. and Nakane, M. 2012. Can Women Save Japan? IMF Working Papers, [online] 12(248), pp.18-24. Available at: https://www.imf.org/ external/pubs/ft/wp/2012/wp12248.pdf.

Stewart, J. J., Hedge, D. M., \& Lester, J. P. 2008. Public policy: An evolutionary approach (3rd ed.). Boston: Thomsom Wordsworth.

Subarsono. AG. 2011. Analisis Kebijakan Publik: Konsep. Teori dan Aplikasi. Yogyakarta: Pustaka Pelajar.

Suparno. 2017. Implementasi Kebijakan Publik Dalam Praktek. Jakarta: Dwiputra Pustaka Jaya.

Toru, S. 2013. Population Studies in Japan. Low Fertility and Low Population Aging in Japan and Eastern Asia(p. 1). Tokyo: Springer.

Van Meter, D. S., \& Van Horn, C. E. 1975. The Policy Implementation Process: A Conceptual Framework. Administration 
\& Society, 6(4), 445-488. https://doi. org/10.1177/009539977500600404.

Wallace Foundation. Workbook B: Conducting Secondary Research. [Other information restricted]. Retrieved June 2020 online from http://www. wallacefoundation.org/

Yoshino, N. and Taghizadeh Hesary, F. 2014. Three Arrows of 'Abenomics' and the Structural Reform of Japan: Inflation Targeting Policy of the Central Bank, Fiscal Consolidation, and Growth Strategy. SSRN Electronic Journal, [online] pp.3-18. Available at: https://www.researchgate.net/ publication/264418942_Three_Arrows of Abenomics_and the Structural Reform_of_Japan_Inflation_Targeting Policy_of_the_Central_Bank_Fiscal_ Consolidation_and_Growth_Strategy.

Yoshio, H. 2018. Analysis of Japan's Labor Economy 2017. Japan Labor Issue, Vol 2, No.7.

Yuiko, I. 2015. Policy Implementation Studies: The Case of Eliminating Daycare Waiting Lists in Japan. WINPEC Working Paper Series No.E1501, 5-52.

Yunchen, T. 2018. Is Japan Becoming a Country of Immigration? Why More Foreign Labor Doesn't Imply Liberalization. The Council on Foreign Relations Journal, 1-3.

Zimmerman, K.F. 2005. European labour mobility: challenges and potentials. De Economist, 153(4), 425-450. doi: 10.1007/s10645-005-2660-x. 